\title{
Partisipasi Masyarakat Dalam Implementasi Kebijakan Desentralisasi Administratif di Sub Distrik Pante-Makassar
}

\section{Community Participation in the Implementation of Administrative Decentralization Policy in the Sub-District of Pante-Makassar}

\author{
Agustinho Elu, Teguh Yuwono, Tri Yuningsih \& Teuku Afrizal* \\ Magister Administrasi Publik, Fakultas Ilmu Sosial dan Ilmu Politik, Universitas Diponegoro \\ Diterima: 09 Juni 2021; Direview: 01 Agustus 2021; Disetujui: 19 Agustus 2021
}

*Coresponding Email: teukurian@lecturer.undip.ac.id

\begin{abstract}
Abstrak
Penelitian ini memfokuskan pada Implementasi Kebijakan Desentralisasi Administratif di Sub Distrik Pante Makassar, Wilayah Administratif Espesial Oe-Cusse Ambeno. Penelitian ini bertujuan untuk menganalisis Implementasi Kebijakan desentralisasi Administratif Di Sub Distrik Pante-Makassar, Wilayah Administratif Especial Oe-Cusse Ambeno, Timor Leste dan faktor-faktor yang mempengaruhi implementasi kebijakan desentralisasi administrative Di Sub Distrik Pante-Makassar, Wilayah Administratif Especial Oe-Cusse Ambeno, Timor Leste. Pendekatan yang digunakan oleh peneliti adalah menggunakan pendekatan atau metode kualitatif dengan lokasi penelitian pada Pemerintahan Sub Distrik Pante Makassar, Wilayah Administratif Espesial Oe-Cusse Ambeno. Data Primer diperoleh dengan melakukan penelitian langsung terhadap objek penelitian dengan menggunakan teknik pengumpulan data observasi, interview atau wawancara. Data sekunder diperoleh melalui studi pustaka untuk mengumpulkan data - data melalui buku-buku, peraturan-peraturan, dan dokumen yang ada relevansinya dengan penelitian. Responden penelitian ini adalah seluruh masyarakat Distrik Pante Makassar sebagai sasaran implementasi desentralisasi Administratif. Teknik pengambilan sampel secara aksidental. Hasil penelitian menunjukan bahwa Implementasi Kebijakan Desentralisasi Administratif menunjukan bahwa masyarakat Subdistrik Pante Makassar berpartisipasi dalam pengambilan keputusan. Masyarakatpun ikut berpartisipasi dalam implementasi kebijakan desentralisasi, masyarakat Subdistrik Pante Makassar ikut memanfaatkan hasil implementasi kebijkan desentralisasi namun dalam evaluasi kebijakan masyarakat kurang berpartisipasi dalam mengevaluasi kebijkan yang telah diimplementasiakan.
\end{abstract}

Kata Kunci: Partisipasi Masyarakat; Implementasi Kebijakan; Desentralisasi Administratif.

\begin{abstract}
This research focuses on the Implementation of Administrative Decentralization Policy in the Pante Makassar SubDistrict, Oe-Cusse Ambeno Special Administrative Region. This study aims to analyze the implementation of the administrative decentralization policy in the Pante-Makassar sub-district, the Special Administrative Region of Oe-Cusse Ambeno, Timor Leste and the factors that influence the implementation of the administrative decentralization policy. The approach used by the researcher is to use a qualitative approach or method with the research location in the Pante Makassar Sub-District Government, Oe-Cusse Ambeno Special Administrative Region. Primary data is obtained by conducting direct research on the object of research using observation, interview or interview data collection techniques. Secondary data is obtained through literature study to collect data through books, regulations, and documents that are relevant to the research. The respondents of this study were the entire community of the Pante Makassar District as the target of the implementation of Administrative decentralization. Accidental sampling technique. The results showed that the implementation of the Administrative Decentralization Policy showed that the people of the Pante Makassar Sub-district participated in decision making. The community also participates in the implementation of the decentralization policy, the people of the Sub-district of Pante Makassar also take advantage of the results of the implementation of the decentralization policy, but in evaluating the policy, the community does not participate in evaluating the policies that have been implemented.
\end{abstract}

Keywords: Community Participation; Policy Implementation; Administrative Decentralization.

How to Cite: Elu, A., Yuwono, T., Yuningsih, T., \& Afrizal, T. (2021). Partisipasi Masyarakat Dalam Implementasi Kebijakan Desentralisasi Administratif Di Sub Distrik Pante-Makassar. Journal of Education, Humaniora and Social Sciences (JEHSS). 4(2): 968-973 


\section{PENDAHULUAN}

Wilayah Administratif Especial Oe-Cusse Ambeno merupakan Salah satu distrik dari Negara Timor Leste yang secara geografis terpisah dari duabelas distrik lainnya. Oecusse, adalah sebuah distrik di Timor Leste. Daerah ini merupakan eknklave pesisir di bagian barat pulau Timor, terpisah dari negara Timor Leste oleh kawasan Timor Barat milik Provinsi Nusa Tenggara Timur. Ibu kota Oe-Cusse Ambeno ialah Pante Makasar (Kota Oe-cussi).

Dilihat dari letak geografisnya yang terpisah dari distriklainnya maka pemerintah perlu mengimplementasikan kebijakan desentralisasi Administratif demi mempercepat pembangunan di daerah Enclave tersebut. Salah satu faktor keberhasilan implementasi kebijakan desentralisasi di Subdistrik Pante-makassar yaitu dengan adanya partisipasi dari masyarakat kecamatan Pante Makassar itu sendiri. Menurut Sastrodipoetro (dalam Ainur Rohman, 2009:45) menyatakan bahwa partisipasi sebagai keterlibatan yang bersifat spontan yang disertai kesadaran dan tanggung jawab terhadap kepentingan kelompok untuk mencapai tujuan tertentu.

Belakangan ini, baik instansi pemerintah, perguruan tinggi, lembaga swadaya masyarakat, atau bahkan masyarakat, kebijakan desentralisasi menjadi topik yang paling menarik dalam diskusi publik. Antusiasme kelompok-kelompok yang berbeda ini untuk membahas kebijakan desentralisasi sangat beralasan karena secara langsung maupun tidak langsung mempengaruhi kehidupan mereka.

Secara umum, desentralisasi mengacu pada pendelegasian (pengalihan) wewenang dan tanggung jawab untuk menangani fungsi publik dari pemerintah pusat kepada pemerintah daerah. Alasan utama mendorong desentralisasi daripada sistem terpusat adalah karena pemerintah pusat dianggap tidak mampu memberikan layanan publik kepada warganya. Pasalnya, model sentralisasi tidak merepresentasikan masyarakat lokal, karena pemerintah memberlakukan keseragaman di setiap daerah.

Dengan desentralisasi, pemerintah daerah akan memainkan peran penting dalam pembangunan karena memiliki kewenangan dan tanggung jawab untuk melaksanakan pembangunan masyarakat di wilayah kewenangannya. Karena pemerintah daerah diyakini memiliki pemahaman yang lebih baik tentang kebutuhan dan pilihan warganya, dalam rangka peningkatan kesejahteraan masyarakat lokal, proses pembangunan model desentralisasi harus lebih efektif daripada model kebijakan sentralisasi.

Negara Timor Leste memperoleh kembali kemerdekaannya pada tahun 2002, dan negara Timor Leste menganut prinsip desentralisasi. Pasal 5 (Desentralisasi), Pasal 71 (Pengaturan Organisasi Pemerintah) dan Pasal 72 (Pemerintahan Daerah) Undang-Undang Dasar Republik Demokrasi Timor Leste mengatur hal ini.

Salah satu alternatif kebijakan yang telah ditetapkan adalah Lei no 3/2014, de 18 de Junho, criou a Região Administrativa Especial de Oe-Cusse Ambeno e a Zona Económica Especial de Economia Social de Oe-Cusse Ambeno e Ataúro, definindo as bases que as regem, de acordo com o previsto na Constituição da República Democrática de Timor-Leste (Undang-undang no. 3/2014, tertanggal 18 Juni, membentuk Daerah Administratif Khusus Oe-Kussi Ambeno dan Zona Ekonomi Khusus Sosial Ekonomi Oe-Kussi Ambeno dan Ataúro, menetapkan basis yang mengaturnya, sebagaimana diatur dalam Konstitusi Republik Demokratik Timor-Leste).

Secara umum, terdapat tiga (tiga) bentuk desentralisasi, yaitu desentralisasi politik, desentralisasi administrasi, dan desentralisasi fiskal. Namun, artikel ini memfokuskan penelitiannya pada desentralisasi administratif, yang diartikan sebagai kekuasaan pengambilan keputusan berada di bawah pemerintahan tingkat bawah terkait dengan kebijakan publik dan penyediaan layanan publik (Schneider 2003: 37-38; Hossain 2010: 3). Secara umum istilah desentralisasi administratif dikenal dengan 3 (tiga) istilah yang berbeda, yaitu dekonsentrasi, delegasi dan devolusi (Litvack, 1999).

Sehubungan dengan hal tersebut, Litvack berkeyakinan bahwa fungsi utama desentralisasi administratif adalah meningkatkan kemampuan pemerintah daerah dalam memberikan pelayanan publik yang berkualitas guna mendukung pembangunan ekonomi dan meningkatkan kesejahteraan masyarakat setempat. Desentralisasi administrasi dalam UU No. 3/2014 tercermin 
dari pembagian urusan antara pemerintah pusat dan daerah yang pada akhirnya memunculkan fungsi-fungsi wajib yang dijalankan oleh pemerintah daerah.

Implementasi kebijakan desentralisasi, pemerintah daerah mempunyai wewenag yang kuat. Namun, pemerintah daerah juga dihadapkan pada berbagai persyaratan dari masyarakat atas layanan yang mereka berikan. Tuntutan masyarakat terhadap pelayanan yang disediakan pemerintah tidak hanya dilihat dari aspek kuantitatif, tetapi juga dari aspek kualitas. Kualitas layanan merupakan masalah inti, yang kini telah muncul di berbagai daerah. Penetapan kualitas pelayanan di elaborasi dalam tiga sudut pandang. Pertama: pengaruh kebijakan pemerintah yang melaksanakan mandat dari masyarakat untuk melayani (amanah). Kedua kualitas yang ditetapkan ketiga, penilaian terhadap birokrasi yang melakukan penilaian (Deddy Mulyadi, dkk; 2016).

Região Administrativo Especial Oe-Cusse Ambeno (RAEOA) merupakan bagian dari kesatuan sistem pemerintahan nasional Timor Leste yang merupakan daerah otonom dengan fungsi desentralisasi, antara lain desentralisasi Administratif, dan desentralisasi fiskal. Pembahasan dalam penelitian ini sebenarnya lebih menitikberatkan pada desentralisasi administrasi yang dilaksanakan oleh Pemerintah RAEOA dalam memberikan pelayanan publik yang berkualitas.

\section{METODE PENELITIAN}

Kajian penelitian ini merupakan penelitian kualitatif, Menurut Moleong (2010:6) adalah penelitian yang bermaksud untuk memahami fenomena tentang apa yang dialami oleh subjek penelitian misalnya perilaku, persepsi, motivasi, tindakan dan lain-lain, secara holistik dan dengan cara deskripsi dalam bentuk kata-kata dan bahasa, pada suatu konteks khus yang alamiah dan dengan memanfaatkan berbagai meteode alamiah. Lokasi penelitian ini di sub Distrik Pante Makassar Wilayah Administratif Espesial Oe-Cusse Ambeno. Data Primer diperoleh dengan melakukan penelitian langsung terhadap objek penelitian dengan menggunakan teknik pengumpulan data observasi, interview atau wawancara, yaitu melakukan tanya jawab secara langsung dengan informan yang telah dipilih dalam hal pengumpulan informasi yang relavan (Tabel 1).

Tabel 1. Informan dalam penelitian ini adalah

\begin{tabular}{clc}
\hline No & \multicolumn{1}{c}{ Responden } & Jumlah \\
\hline 1 & Camat Sub Distrik Makassar & 1 orang \\
\hline 2 & Kepala Desa & 5 Orang \\
\hline 3 & Masyarakat & 5 Orang \\
\hline
\end{tabular}

Sumber: Data Olahan penulis, 2021

Data sekunder diperoleh melalui study pustaka untuk mengumpulkan data - data melalui buku-buku, peraturan-peraturan, dan dokumen yang ada relevansinya dengan penelitian. Subjek penelitian adalah orang-orang yang mengetahui dan memiliki berbagai informasi pokok, menjadi informan yang akan memberikan berbagai informasi yang diperlukan selama proses penelitian. Teknik analisis data yang digunakan dalam penelitian ini adalah teknik triangulasi, teknik triangulasi adalah teknik pemeriksaan keabsahan data memanfaatkan sesuatu yang lain. Di luar data itu untuk keperluan pengecekan atau sebagai pembanding terhadap data itu.Teknik triangulasi yang paling banyak digunakan adalah pemeriksaan melalui sumber lainnya.

\section{HASIL DAN PEMBAHASAN}

\section{Partisipasi Masyarakat dalam Pengambilan Keputusan}

Hak setiap orang untuk memperoleh informasi sangat relevan untuk meningkatkan kualitas keterlibatan masyarakat dalam proses pengambilan keputusan publik. Setiap kebijakan publik yang diambil pemerintah akan lebih bermakna ketika mengedepankan partisipasi masyarakat sejak proses perencanaannya. Namun, partisipasi masyarakat tidak banyak berarti tanpa jaminan keterbukaan informasi publik.

Berdasarkan hasil penelitian tentang partisipasi masyarakat dalam pengambilan keputusan menunjukan bahwa terdapat dua macam partisipasi, yakni: partisipasi tidak lansung dan 
partisipasi lansung. Partisipasi tidak lansung melalalui media cetak dan media eletronik. Dengan adanya media cetak dan media elektronik masyarakat sering berpartisipasi dalam diskusi-diskusi melalui talk show dan input-input masyarakat yang diterbitkan melalui media-media cetak. Persoalan yang paling mendasar adalah akses ke media cetak dan elektronik yang tidak dimiliki secara seimbang oleh setiap warga masyarakat dapat mengakibatkan distorsi dalam pengambilan kebijakan publik. Partisipasi lansung, salah satu contohnya adalah dengar pendapat yang dilakukan antar warga masyarakat dengan pihak eksekutif atau legislatif dalam rangka mencapai kesepakatan atas suatu kebijakan tertentu. Partisipasi langsung yang melibatkan warga masyarakat di ruang publik selain untuk memberi masukan kepada eksekutif dan legislatif dalam mengambil kebijakan juga dapat digunakan untuk melakukan tekanan- tekanan politik terhadap kedua lembaga tersebut. Tekanan-tekanan itu dapat berupa permintaan sekelompok orang untuk merealisasikan kepentingan mereka, mengevaluasi kebijakan tertentu atau membatalkan undangundang, dan lain-lain.

\section{Partisipasi Masyarakat dalam Pelaksanaan}

Adanya partisipasi masyarakat terhadap implementasi kebijakan publik merupakan wujud nyata dukungan masyarakat terhadap pemerintah. Partisipasi masyarakat terhadap pelaksanaan kebijakan publik merupakan proses dan wujud partisipasi politik masyarakat dalam kehidupan kenegaraan. Kebijakan publik tidak akan terlaksana secara efektif jika tidak ada partisipasi dari masyarakat. Perlu disadari bahwa setelah kebijakan publik terbentuk sering kali kebijakan publik yang terdapat dalam masyarakat tidak sesuai dengan harapan yang telah ditetapkan oleh pemerintah. Oleh karena itu, setiap kebijakan publik yang dikeluarkan oleh pemerintah diupayakan mendapatkan dukungan masyarakat. Adanya partisipasi masyarakat dapat menunjukkan tingkat dukungan masyarakat terhadap kebijakan publik.

"Berdasarkan hasil penelitian dalam variabel partisipasi masyarakat dalam pelaksanaan desentralisasi Administrasi "secara umum masyarakat Kecamatan Pante Makassar sangat menyadari betapa penting partisipasinya sebagai agen perubahan untuk dapat membantu pemerintah daerah terlebih khusus dalam program desentralisasi Administrasi, karena di satu sisi mereka adalah pejuang bagi daerah guna menunjang perkembangan dan pembangunan daerah. Masyarakat sangat antusias dalam merespon setiap pembangunan siap untuk dilaksanakan dari hasil yang sudah terprogram dalam musyawarah rencana implementasi desentralisasi sesuai dengan kewenangan yang diamanatkan kepada mereka selaku pemerintah daerah agar dapat melaksanakan pembangunan, mereka juga rela memberikan sumbangsi baik dalam bentuk pikiran, fisik, finansial mapun fasilitas yang dimilikinya semata-mata demi keadilan sosial dan kesejahteraan bagi masyarakat Kecamatan Pantemakassar terutama dalam pembangunanpembangunan yang ada. Namun di sisi lain ada beberapa masyarakat yang masih kurang menyadari betapa pentingnya partisipasi mereka sebagai garda terdepan untuk menunjang terlaksananya setiap pembangunan sehingga masih bersikap apatis dan masa bodoh terhadap setiap kebijakan dalam pembangunan yang ada."

Dalam proses pembangunan, tahap implementasi sebagai kelanjutan dari proses perencanaan akan menentukan apakah suatu kebijaksanaan atau program pembangunan dapat terwujud sesuai dengan perencanaan dan perwujudannya mencapai hasil sesuai dengan tujuan suatu program pembangunan berupa peningkatan kesejahteraan. Masyarakat daerah dengan pengetahuan serta pengalamannya menjadi kekuatan yang sangat berarti dalam mengimplementasikan pembangunan, karena masyarakat daerah yang memahami masalahmasalah yang dihadapi serta potensi yang dimiliki oleh daerahnya. Masyarakat memiliki kedaulatan yang cukup luas untuk menentukan orientasi dan arah kebijakan pembangunan yang diinginkan. Norma-norma kedaulatan sepantasnya dibangun sebaga kebutuhan bersama masyarakat dan bebas dari kepentingan individu dan atau kelompok. 


\section{Partisipasi Masyarakat dalam Menerima Manfaat}

Suatu program itu bermanfaat ketika memang dilaksanakan untuk kebutuhan masyarakat dan manfaatnya bisa dirasakan oleh masyarakat, berdasarkan hasil penelitian tentang variabel Partisipasi Masyarakat dalam menerima Manfaat, menunjukan bahwa manfaat dari desentralisasi Administrasi sangat terasa terbantu karena sebelum kebijakan desentralisasi diimplementasikan semua program terpusat dan birokrasi pemerintahannyapun sangat berbelit-belit, namun setelah implementasi desentralisasi semua yang berhubungan dengan administrasi dan pembangunan daerah diberikan kepada pemerintah daerah untuk megatur rumah tangganya sendiri sesuai dengan kebutuhan masyarakat setempat, memberikan pelayanan yang efektif kepada masyarakat daerah. Namun dalam implementasi desentralisasi administratisi juga masih terdapat banyak kendala karena penggunaan lahan masyarakat untuk pelebaran jalan raya dan pembangunan infrastruk lainnya sampai saat ini belum mendapat ganti rugi untuk lahan mereka.

Desentralisasi sangat bermanfaat apabila dilihat dari manfaat administrasi, karena pemerintah memberikan wewenang kepada daerah untuk mengatur rumah tangganya sesuai dengan situasi dan kondisi masyarakat setempat. Partisipasi masyarakat memang harus diakui dapat dikatakan bahwa masyarakat sudah ikut berpartisipasi didalam implementasi desentralisasi di Sub Distrik Pante-Makassar sebagaimana harapan pemerintah daerah adalah membawa kehidupan yang baik di daerah ini salah satunya caranya memposisikan masyarakat di dalam perencanaan dan pengerjaan pembangunan daerah karena semua manfaatnya adalah untuk masyarakat dari masyarakat yang memberikan gagasan dan implementasi oleh masyarakat dan pengaruh dan keuntungannya juga akan dinikmati semua warga masyarakat.

\section{Partisipasi dalam Evaluasi}

Evaluasi terhadap pelaksanaan program dimaksudkan untuk dapat meningkatkan efektivitas kegiatan, memecahkan masalah yang tidak terduga, dan meyakinkan bahwa usaha yang dilakukan mengarah pada hasil yang diinginkan. Evaluasi terhadap kegiatan yang telah selesai dimaksudkan untuk mengukur atau menilai efektivitas keseluruh pelaksanaan program, kinerja, capaian dan hasil program, sehingga dapat dibuat keputusan mengenai kelanjutan suatu program.

Berdasarkan hasil penelitian pada indikator ini menunjukan bahwa keikutsertaan masyarakat dalam bentuk kritik terhadap implementasi desentralisasi, memberikan argumen maupun saran terhadap implementasi desentralisasi, dan yang terpenting adalah memberikan penilaian yang kemudian disampaikan kepada pemerintah sebagai bahan untuk evaluasi, masyarakat kurang berpartisipasi dalam evaluasi implementasi kebijakan desentralisasi secara lansung kepada pemerintah, karena biasanya yang terjadi eksekutif sering berkonsultasi dengan masyarakat hanya pada tahap perencanaan dan implementasi namun setelah implementasi pemerintah jarang berkomunikasi dengan masyarakat.

Partisipasi masyarakat dalam evaluasi kebijakan merupakan indikator yang krusial karena dengan adanya hasil kebijakan dapat mempengaruhi masa depan kebijakan dan sebagai penentu kebijakan selanjutnya sehingga kebijakan tersebut terus diimplementasikan atau perlu diperbaiki bahkan kebijakan tersebut bisa dibatalkan.

\section{SIMPULAN}

Berdasarkan hasil penelitian di atas dapat disimpulkan bahwa dalam pengambilan keputusan masyarakat sering dilibatkan baik secara lansung dan tidak lansung. Dalam pelaksanaan desentralisasi administrasi masyarakatpun antusias diikutsertakan dalam implementasi kebijakan desentralisasi. Antusias dalam merespon setiap pembangunan siap untuk dilaksanakan dari hasil yang sudah terprogram dalam musyawarah, rencana implementasi desentralisasi sesuai dengan kewenangan yang diamanatkan kepada mereka selaku pemerintah daerah agar dapat melaksanakan pembangunan, masyarakat rela memberikan sumbangsi baik dalam bentuk pikiran, fisik, finansial mapun fasilitas yang dibutuhkan. Masyarakat memanfaatkan semua hasil dari desntralisasi seperti: pelayanan, infrastruktur, agrikultur dan lain-lain yang ada kaitannya dengan partisipasi masyarakat. Dalam evaluasi kebijakan masyarakat tidak diberikan 
kesempatan untuk memberikan evaluasi kepada masyarakat, karena tidak ada informasi yang jelas tentang siapa yang terlibat dalam evaluasi kebijakan tersebut.

Masyarakat Sub distrik Pante-Makassar, Wilayah Administratif Espesial Oe-cusse Ambeno perlu merubah paradigma dan lebih menyadari bahwa begitu pentinnya partisipasi dalam setiap proses Implementasi desentralisasi administrasi guna keberhasilan pembangunan, oleh karena itu, 1. Diharapkan masyarakat dapat merubah kerangkah berpikir untuk lebih meningkatkan partisipasi khususnya dalam setiap pengambilan keputusanguna menunjang setiap program pemerintah yang sudah ditetapkan.2. Diharapkan masyarakat dapat lebih menyadari betapa pentingnya partisipasi dalam Implementasi Kebijakan Desentralisasi. 3. Diharapkan pemerintah Sub Distrik Pante Makassar dapat membanguna proses kesadaran kepada sebagian masyarakat yang tidak mau terlibat dalam proses implementasi kebijakan desentralisasi sehingga ikut terlibat atau menjadi aktif berpartisipasi dalam setiap pembangunan, melalui sosialisasi kepada masyarakat. 4.Diharapkan Pemerintah perlu mengikutsertakan masyarakat dalam membuat evaluasi kebijakan. Karena evaluasi merupakan penentu kebijakan selanjutnya.

\section{DAFTAR PUSTAKA}

Ardhana, I.K. (2005), Pemerintahan pusat dan swapraja: Masalah sentralisasi dan desentralisasi." Jurnal Masyarakat dan Budaya, 7(2): 43-56.

Ayee, J. R. A. (2008), 'Decentralization and Governance in Ghana', Regional Development Dialogue, 29(2): 3554.

Blair, H. (2000), USAID and Democratic Decentralization: Taking the Measure of an Assistance Programme. Democracy Assistance: International Co-operation for Democratization (Democratization Studies 5).

Blunt, P, Turner, M, and Lindroth, H. (2012), Patronage's progress in post-Soeharto Indonesia." Public Administration and Development 32(1): 64-81.

Blunt, P. and Turner, M. (2007), 'Decentralization and Poverty Reduction in the Asia Pacific', in G. S. Cheema and D. A. Rondinelli (eds.), Decentralising Governance: Emerging Concepts and Practices, Washington, DC: Brookings Institution Press.

Cheema, G.S. and Rondinelli, G.D. (eds.) (2007), Decentralizing Governance: Emerging Concepts and Practices, Washington, DC; Brookings Institute Press.

Konstitusi Republik Demokratis Timor Leste, 2002, UNDP, Dili Timor Leste.

Moleong, (2010). Metode Penelitian Kualitatif. Bandung: PT .Remaja Rosdkarya.

Mulyadi, D. (2016), Implikasi Kebijakan Kelembagaan Terhadap Aparatur \& Pelayanan Publik." Jurnal Ilmu Administrasi: Media Pengembangan Ilmu dan Praktek Administrasi, 13(3): 389-400.

Purnamasari, I. (2008), Studi partisipasi masyarakat dalam perencanaan pembangunan di Kecamatan Cibadak Kabupaten Sukabumi. Diss. program Pascasarjana Universitas Diponegoro.

Robinson, M. (2007), 'Does Decentralization improve Equity and Efficiency in Public Service Delivery Provision?', Institute of Development Studies Bulletin, 38(1): 7-17.

Rohman, A. (2009), Politik, Partisipasi dan demokrasi dalam Pembangunan. Malang: Averoes.

Rondinelli, D.A. (1981), Government decentralization in comparative perspective: theory and practice in developing countries. International review of administrative sciences 47(2): 133-145.

Schneider, A. (2003), "Decentralization: Conceptualization and measurement." Studies in comparative international development, 38(3): 32-56.

Solekhan, M. (2012). Penyelenggaraan Pemerintahan Desa. Malang: Setara Press

Solekhan, M. (2012), Penyelenggaraan pemerintahan desa: berbasis partisipasi masyarakat dalam membangun mekanisme akuntabilitas. Setara.

Undang-undang No 3/20014, 18 Juni, Pembentukan Wilayah Administratif Espesial Oe-Cusse Ambeno. 